\title{
HIBRIDISASI HEAVY METAL DAN ISLAM: TRANFORMASI BAND METAL SEBAGAI LAHIRNYA METAL ISLAM DI INDONESIA
}

\author{
Anis Sujudi \\ Program Studi Hubugan Internasional, Universitas Airlangga; \\ email: sujudiomplok@gmail.com
}

\begin{abstract}
This paper aims to analyze the hybridition of heavy metal and Islam through Islamic metal in Jakarta, Bandung and several other places in Indonesia, which have changed the metal scene in Indonesia. This paper uses a descriptive discussion with qualitative methods and concepts of hybridization and cosmopolitanism. The results of this study indicate, Islamic metal occurs, because of the low conflict between government, Islam and metal. The presence of Islamic metal in the metal scene changes community patterns, habits and identity in metal, by applying values based on Islam. The existence of Islamic metal as a new sub-genre incites the pros and cons of Islam and the metal scene, because it considers the phenomenon of exclusivity in inclusiveness in metal.
\end{abstract}

Keywords: $\quad$ cosmopolitanism, hybridization, Islamic and Indonesian heavy metal

\begin{abstract}
Tulisan ini bertujuan menganalisa hibridisasi heavy metal dan Islam melalui band-band metal Islam yang lahir di Jakarta, Bandung dan beberapa tempat lainnya di Indonesia, yang telah mengubah skena metal di Indonesia. Tulisan ini menggunakan pendekatan deskriptif dengan metode kualitatif dan kerangka konsep hibridisasi dan kosmopolitanisme. Hasil dari penelitian ini menujukan, kelahiran metal Islam terjadi, sebab rendahnya tendesi atau gesekan antara pemerintah dan Islam dengan metal. Kehadiran metal Islam dalam skena metal mengubah pola komunitas, kebiasaan dan identitas dalam skena metal dengan menerapkan nilai berdasarkan Islam. Keberadan metal Islam sebagai sub genre baru menimbulkan pro dan kontra dari kalangan Islam dan skena metal pada awalnya, karena dianggap menimbulkan fenomena eksklusifitas dalam inklusifitas di metal.
\end{abstract}

Kata Kunci: heavy metal Islam dan Indonesia, hibridisasi, kosmopolitanisme 


\section{Pendahuluan}

Tulisan ini membahas terkait hibridisasi heavy metal dan Islam di Indonesia dalam konteks lahirnya band-band metal Islam. Budaya heavy metal berdasarkan musiknya memiliki sejarah panjang melalui penggabungan beberapa genre musik, namun istilah heavy metal mulai dikenal pada 1960-an melalui karya band-band seperti Deep Purple, Led Zepplin, Iron Butterfly, Vanilla Fudge, Jimmi Hendrix dan terutama Black Sabbath (Hjelm, Kahn-Harris, \& LeVine., 2011). Budaya heavy metal menjadi fenomena baru pada musik rock ketika itu dan menjadi genre yang kontroversial baik dari segi bermusik dan gaya hidup musisinya. Bahkan metalhead, sebutan bagi fans musik metal, selalu dikaitkan dengan seks bebas, alkohol dan pemujaan setan (Weinstein, 2000). Kuatnya asosiasi heavy metal dengan seks bebas, alkohol dan pemujaan setan menimbulkan hubungan buruk antara agama Kristen pada awal kemunculanya di Barat.

Hubungan buruk itu tergambar seperti pada genre black metal di Norwegia. Para metalhead di sana menggunakan semangat sub budaya metal tersebut untuk melakukan gerakan subversif dengan membakar gereja-gereja sebagai bentuk perlawanan dan protes terhadap nilai-nilai kekristenan, yang mereka anggap telah membatasi kebebasan individu melalui nilai-nilai agama. Sebab itu metalhead dari black metal mengalami banyak penolakan, perlawanan dan penangkapan, karena dinilai telah melakukan tindakan melanggar hukum (Bossius, Thomas; Häger, Andreas; Kahn-Harris, Keith., 2011).

Kontroversi dan penolakan terhadap metal juga terjadi di negara-negara Islam. Meskipun demikian, penolakan yang terjadi bukan karena metalhead melakukan gerakan ekstrim. Levine (2008.) menggambarkan penolakan budaya metal oleh pemuka agama dan pemerintah di negara-negara Islam, seperti yang terjadi di Libanon, Mesir dan Iran. Penolakan itu karena budaya metal dianggap membuat para pemuda di negara-negara tersebut berprilaku tidak Islami. Hal serupa terjadi di Malaysia yang memiliki pemahaman Islam yang lebih lembut. Berdasarkan fatwa yang dikeluarkan sebuah otoritas dewan fatwa di Malaysia menyatakan "budaya musik black metal melanggar hukum syariat Islam dan dinyatakan haram", sehingga mendengar musik metal dan menjadi seorang metalhead yang beraliran black metal dianggap kriminal (Levine, 2009) Negara-negara Islam seperti Libanon, Mesir, Iran dan Malaysia melakukan penolakan terhadap musik metal karena mengalami kepanikan moral, serta takut kehilangan identitas dan nilai Islam yang mereka imani. 
Indonesia, negara dengan mayoritas muslim, tidak menyikapi kehadiran metal sebagai bentuk kepanikan moral dan ancaman terhadap identitas seperti di negara-negara Islam di atas. Bahkan pada tahun 2010 geliat musik metal di Indonesia diwarnai dengan lahirnya salam satu jari yang dipelopori oleh vokalis band metal Tengkorak, kemudian dikuti band metal Purgatory dan band-band cadas lainnya (Hidayatullah, 2018). Dari dua band metal tersebut Purgatory dan Tengkorak membawakan lirik-lirik bernadakan dakwah dan bernilaikan Islam. Hal ini sangat jelas membedakan mereka dengan band metal arus utama lainnya. Kemunculan salam satu jari membentuk hubungan baru antara musik metal dan Islam sebagai kepercayaan agama. Musik metal yang selama ini diperlihatkan sebagai budaya underground yang identik dengan bentuk perlawanan dan kritik terhadap politik, agama dan berbagai bentuk kemapanan. Bertransformasi membawakan nilai agama yang sebelumnya saling berbenturan dengan budaya underground. Fenomena salam satu jari juga tergambar dalam white metal dalam Kristen yang juga berkembang di beberapa negara Eropa (Thomas Bossius, Häger, Andreas, \& Kahn-Harris, 2011). Kesamaan antara band-band metal Islam dan white metal yaitu samasama membawakan pesan agama menggunakan musik metal. Istilah salam satu jari berasal dari komuitas atau gerakan satu jari atau one finger movement yang didirikan oleh Ombat pada 2010 di Jakarta sebagai gerakan atau perkumpulan para metalhead, fans underground dan anak-anak muda hijrah ${ }^{1}$ yang memiliki ketertarikan lebih tentang Islam (Saefullah, 2017). Kemunculan salam satu jari menjadi awal lahirnya band-band metal Islam, kemudian diikuti di daerah lain seperti di Bandung, Purbalingga, Medan dan Malang.

Argumetasi penulis melihat hibridisasi metal dan Islam ini dilatarbelakangi oleh sikap dan keadan Islam di Indonesia yang lebih moderat dan dekat dengan budaya. Meskipun begitu, tidak bisa dipungkiri ada faktor lain, seperti perubahan sosial politik yang juga memengaruhi lahirnya metal Islam. Pada penelitian terdahulu yang terkait dengan metal Islam, oleh Saefullah (2017) melihat metal Islam di skena² underground terjadi karena hadirnya neoliberal, hilangnya semangat politik kiri dan kebangkitan Islam

\footnotetext{
${ }^{1}$ Hijrah merupakan berpindah atau menyingkir untuk sementara waktu dari suatu tempat ke tempat lain yang lebih baik, dengan alasan tertentu (keselamatan, kebaikan, dan sebagainya), tetapi dalam majas lain hijrah di artikan menjauh dari dosa (Attaki dalam Saefullah 2017)

2 Scene atau skena musik menunjuk konteks di mana kelompok produsen, musisi, dan penggemar secara kolektif berbagi selera musik bersama mereka dan secara kolektif membedakan diri dari orang lain.(Bennett and Peterson 2004 hal. 01).
} 
konservatif. Kemudian oleh James dan Walsh (James \& Walsh., 2019), yang mencoba mengidentifikasi metal Islam di Indonesia, menjadi dua kelompok, konservatif dan sekuler. Berbeda dengan dua penelitian di atas, tulisan ini menggunakan pendekatan budaya untuk memahami hibridisasi metal Islam di Indonesia, terutama bagaimana selama ini Islam diartikulasikan di Indonesia, sehingga penelitian ini memiliki kesamaan dengan melihat metal Islam sebagai fenomena hibrid, tetapi yang membedakannya dalam penelitian ini penulis melihat ada sikap kosmopolitanisme yang melatarbelakangi hibridisasi metal Islam.

Studi kasus dan tujuan dalam penelitian ini, menganalisa bagaimana band-band metal Islam yang lahir di Jakarta, Bandung dan beberapa tempat lainnya di Indonesia, melalui band dan komunitas-komunitas yang mereka bentuk, telah mengubah skena metal di Indonesia. Tulisan ini menggunakan metode kualitatif dangan cara mengumpulkan data-data sekunder dari buku, jurnal, artikel berita online, akun media sosial, video YouTube dan ditambah dengan data primer melalui wawancara dengan beberapa band metal di Jakarta dan Bandung. Pendekatan yang digunakan adalah deskriptif untuk menjelaskan bagaimana penggabungan heavy metal dengan Islam tersebut.

\section{Kerangka Konseptual}

\section{Hibridisasi dan Kosmopolitanisme}

Globalisasi budaya selama ini membawa tiga analisis yaitu homogenisasi, polarisasi dan hibridisasi. Antara homogenisasi dan polarisasi sebenarnya memiliki pandangan yang hampir sama yaitu melihat globalisasis sebagai arus satu arah yang kuat, dan digambarkan sebagai dominasi arus Barat terhadap non-Barat, akan tetapi keduanya memiliki respons yang berbeda terhadap dampak dari arus tersebut. Berdasarkan tesis utama homognisasi melihat globalisasi sebagai standardization, sedangkan tesis utama dari polarisasi melihat globalisasi sebagai arus satu arah yang berdampak terhadap resistensi arus tersebut. Sehingga terbentuk dua pola yang saling berlawanan (Holton, 2000). Terbalik dengan tesis utama dari homogenisasi dan polarisasi, hibridisai sendiri melihat globalisasi sebagai dua arus yang mengalami percampuran (Philipp, 2012). Dari homogenisasi, polarisasi dan hibridisasi dalam globalisasi esensinya menyadari adanya perbedaan budaya. Dari tiga konsep tersebut tulisan ini menggunakan kerangka pemikiran hibridisasi untuk melihat penggabungan heavy metal dan Islam yang membentuk band metal Islam di Indonesia. 
Homogenisasi selama ini menafikan fenomena ambivalensi dalam globalisasi dan mengabaikan peran penerimaan lokal terhadap budaya Barat, misalnya percampuran budaya Barat dan lokal yang membentuk budaya ketiga yang baru (Pieterse, 2009). Homogenisasi dan polarisasi melihat peneriman lokal tidak pernah memiliki kemampuan penuh untuk menyeimbangi pengaruh Barat melalui percampuran budaya. Meskipun hibridisasi menghasilkan budaya yang baru melalui percampuran lokal dan global yang bisa diterima (Holton, 2000).

Menurut Rowe dan Schelling dalam (Pieterse, 2009) hibridisasi sebagai cara memisahkan bentuk budaya dari praktik yang ada dan bergabung kembali dengan bentukbentuk baru dalam praktik baru. Pada definisi lain hibridisasi budaya juga didefinisikan sebagai interaksi lokal dan global atau glocalization, yang dapat berarti berjalan bersama antara global dengan lokalisme, seperti jargon "Think globally, act locally", sehingga membuat pola identitas dalam budaya menjadi lebih kompleks, karena orang menegaskan loyalitas lokal tetapi ingin berbagi dalam nilai-nilai dan gaya hidup global (Lipschutz, 1992).

Menurut Kraidy (2002), pada saat yang bersamaan hibridisasi merupakan tempat perlawanan terhadap kekutan imperial yang bertujuan untuk pengaburan budaya seperti mengaburkan kekuatan antara pusat dengan pinggiran, hegemoni dengan minoritas, dan destabilisasi atau subversi dari hubungan hierarkis itu. Hibridisasi yang dimaksud sebagai pengaburan kekuatan dominan digunakan untuk mengurangi hegemoni budaya, seperti mengurangi pengaruh budaya Barat dari budaya Timur yang memiliki hubungan asimetris. Dalam dunia Islam misalnya memandang globalisasi sebagai hegemoni Barat terhadap Timur karena mengurangi dan bahkan menghilangkan budaya Timur. Hibridisasi dijadikan jalan tengah di antara keduanya, mengingat sulit sekali untuk menghindari hubungan di antara Islam dan Barat pada era globalisasi ini. Pola interaksi Islam dengan metal yang menggambarkan bagaimana selama ini budaya heavy metal yang diasosiasikan dengan dominasi Barat atau hegemoi Barat dihibridisasi dengan Islam dengan harapan mengurangi dominasi budaya Barat dalam budaya heavy metal atau menggambarkan untuk metal tidak selalu menjadi Barat. Selain itu hibridisasi juga dijadikan sebagai pencegah doktrin budaya rasial dan doktrin nasional karena keduanya seringkali membuat perbedaan budaya menjadi tabu. Berbeda dengan hibridisasi yang membuat perbedaan dalam budaya menjadi sangat relatif, karena hibridisasi memperkuat 
persamaan yang dilahirkan dalam proses percampuran budaya atau "affirmation of similarity" (Pieterse, 2009).

Globalisasi telah memfasilitasi hibridisasi budaya dan difusi makna, simbolik lintas nasional dan lintas budaya. Intensifikasi dalam globalisasi tersebut tampaknya mengarah pada dimensi baru pertukaran budaya, yang pada akhirnya berkontribusi terhadap munculnya masyarakat dunia dengan norma kosmopolitanisme. Globalisasi menginisiasi terjadinya terobosan baru melalui berbagai persinggungan nilai-nilai yang berbeda, sehingga dalam persinggungan tersebut kosmopolitanisme diwujudkan sebagai jalan tengah atau alternatif antara fenomena nasionalisme etnosentris dan multikulturalisme partikularistik (Kersten, 2009).

Menurut Vertovec dan Cohen dalam Kersten (2009) kosmopolitanisme dilihat sebagai sikap, disposisi atau tindakan yang menghormati keanekaragaman budaya, membuat tertarik pada dialog lintas budaya, dan berkomitmen pada bentuk percampuran budaya. Oleh karena itu, kosmopolitanisme mendorong percampuran identitas sebagai respon terhadap potensi untuk menciptakan kombinasi budaya baru (Mehta, 2000). Fokus pada sikap ini konsisten dengan gagasan bahwa kosmopolitanisme melibatkan kompetensi tertentu, cara mengelola makna, dan berbagai bentuk mobilitas. Kwok-Bun (2005) berpendapat bahwa aspek-aspek kosmopolitanisme melalui hibridisasi dan inovasi memungkinkan orang untuk tidak terlalu gigih berpegang pada culture origin mereka dan malah mengeksplorasi kemungkinan-kemungkinan baru yang terbuka (Kwok-Bun, 2005). Nilai kosmopolitanisme tidak hanya menghubungkan kosmopolitanisme dengan hibridisasi budaya tetapi juga membuat atau memproduksi makna baru. Kosmopolitanisme dapat ditemukan dalam pandangan-pandangan afiliasi yang melampaui batas-batas lokal dan nasional yang memberikan kesenangan dalam perbedaan (Hannerz, 2006). Tetapi konteks lokal tetap menjadi hal yang penting karena selama ini lokal dan kosmopolitanisme selalu bersama (Beck, Sznaider, \& Winter, 2003). Melunaknya kegigihan pada budaya origin berdampak terhadap multi identitas yang terjadi sehingga identitas menjadi lebih lunak (Yeĝenoĝlu, 2005). Budaya kosmopolitan sendiri menekankan kecairan identitas individu, untuk membentuk idenitas baru yang berasal dari budaya yang berbeda yang bisa terjadi melalui hibridiasi atau impurity, sehingga perubahan yang terjadi, menjadi hal yang baru dan tidak pernah terduga sebelumnya. Seperti melalui percampuran budaya, ide dan Identitas (Held, 2003). 
Perspektif kosmopolitan sendiri harus melibatkan hubungan dengan pluralitas budaya yang dipahami sebagai entitas yang berbeda. Lebih jauh, kosmopolitanisme dalam pengertian yang lebih ketat mencakup sikap terhadap keanekaragaman itu sendiri, menuju koeksistensi budaya dalam pengalaman individu. Kosmopolitanisme yang lebih asli pertama-tama adalah orientasi, kemauan untuk terlibat dengan yang lain atau menerima keberadaan yang lain (Beck, Sznaider, \& Winter, 2003, p. 26).

Berkaitan dengan tulisan ini, keberhasilan hibridisasi metal dan Islam dalam metal Islam memiliki kesamaan dengan fenomena lahirnya intelektual muslim hibrid dan kosmopolit dalam era globalisasi Kersten (2009) menjelaskan bagaimana kosmopolitanisme dan hibridisasi budaya menjadi alat untuk mengetahui cara-cara cendikawan muslim kontemporer dalam mencapi kesepaktan dengan globalisasi. Para intelektual muslim meminjam secara eklektik atau memilih beberapa saja yang mereka setujui dari ilmu-ilmu pengetahuan Barat. Dengan mendekontekstualisasikan dan menyusun kembali bentuk-bentuk hibrid dari serangkaian konsep dan gagasan dalam konstituensi mereka sendiri. Sehingga para intelektual muslim kontemporer ini sebagai wakil-wakil kosmopolitanisme baru di dunia Muslim.

Hoestery (2012) menjelaskan kosmopolitanisme Islam yang terjadi di masyarakat Islam Indonesia saat ini dilakukan dengan mengartikulasikan norma kosmopolitanisme berdasarkan Islam dan transnasional. Dengan cara mengubah apa yang ada dalam Islam dan bersumber dari Nabi Muhammad SAW sebagai kosmopolitanisme modern, yang menghasilkan sikap seorang Muslim yang beriman dan toleran terhadap perbedaan. Hoestere berpendapat kosmopolitanisme Islam di Indonesia tidak terlepas dari Barat karena mengambil bagian tertentu dari Barat untuk dipilih. Hoestere juga mengatakan kosmopolitanisme Muslim di Indonesia juga coba dijadikan alternatif kosmopolitanisme Islam moderen saat ini di Indonesia. Menurut Hoestere kosmopolitanisme di Indonesia bisa saja berubah dan mencari bentuk kosmopolitanisme baru dalam kontek Islam dan kenabian. Seperti dalam tulisan ini penulis melihat bagaiman konsep hijrah dijadikan sebagai konsep kosmopolitanisme baru yang digunakan untuk berinteraksi dengan hal di luar Islam seperti budaya heavy metal yang melahirkan budaya alternatif baru.

Kesepakatan band metal Islam dan salam satu jari dengan globalisasi serupa dengan yang dijelaskan Kersten dalam menjelaskna cendikawan muslim kontemporer melalui kosmopolitanisme dan hibridisasi dengan mengambil budaya heavy metal 
sebagai budaya baru tetapi disesuaikan dengan kebutuhan metalhead muslim. Sehingga nilai yang terlihat adalah universalisasi partikularisme yang menunjukan ekistensi identitas lokal tetentu dalam nilai global (Robertson, 1992).

Tetapi selama ini hibridisasi dalam globalisasi tidak pernah mempertanyakan bagaimana respons dari pemilik budaya asli yang dihibridisasi, mengingat selama ini budaya juga menjadi bagian yang sensitif dari manusia. Meskipun hibridisasi dapat menyembunyikan ketidak simetrisan dan ketidak merataan dalam proses dan unsur-unsur pencampuran (Pieterse, 2009). Pemahamn terkait hibridisasi sebagai apropisiasi budaya (perampasan budaya) tidak bisa dipungkiri. Hibridisasi sebagai apropiriasi budaya sering menimbukan pro dan kontra antra kedua pemilik budaya asli (origin culture) tersebut (Kraidy, 2002, p. 304). Sehingga hibridisasi dalam sisi lain bisa menimbulkan penolakan oleh pemilik budaya asli atau asal. Potensi ini juga terjadi dalam metal Islam, bagaimana percampuran Islam dan metal bisa mengalami pro dan kontara dari beberapa kalangan muslim dan metalhead sehingga menimbulkan dinamika baru antara kelompok muslim dan metalhead di luar salam satu jari.

\section{Diskusi}

\section{Kelahiran Band- Band Metal Islam di Indonesia}

Globalisasi heavy metal di Indonesia dimulai pada akhir 1980-an dan awal 1990-an. Masa ketika kelas menengah perkotaan Indonesia menjadi semakin kritis dan vokal menentang kekurangan Orde Baru (Rodan, 1996) (Heryanto, 1995). Pada masa itu skena musik underground di Indonesia termasuk musik metal digunakan sebagai gerakan subversif untuk mengkritik pemerintah Orde Baru. Pada 1997 salah satu band asal Surabaya Slow Death mengkritik pemerintah Orde Baru yang masih berkuasa pada saat itu dengan lirik bahasa Inggris dalam lagunya yang mengatakan "There is no difference between Dutch colonialism and the New Order!"', meskipun begitu pemerintah Orde Baru tidak melakukan tidakan apapun terhadap Slow Death, sedikitnya orang Indonesia yang memahami bahasa Inggris membuat lirik lagu ini tidak dianggap sebagai ancaman oleh Orde Baru (Wallach. 2008). Meskipun begitu pemerintah Orde Baru diduga melakukan beberapa intervensi lebih dalam skena underground atau metal di Indonesia.

Pada tahun 1993 ketika konser Metallica rusuh, pemerintah Orde Baru dianggap telah mengkriminalisasi para metalhead, karena diduga menghubungkan musik metal atau rock dan premanisme yang digambarkan dengan pemuda-pemuda bertato. Hal ini 
dianggap serupa seperti operasi Petrus (Penembak misterius) yaitu penembakan terhadap orang bertato yang diduga sebagai preman pada 1980-an (Baulch, 2002). Meskipun begitu Andrei gitaris band metal Siksa Kubur yang ikut menyaksikan konser Metallica pada saat itu, mengatakan kerusuhan sebenarnya terjadi karena kesenjangan ekonomi, sehingga beberapa metalhead tidak mampu membeli tiket, kemudian memaksakan untuk masuk dalam konser dan mengakibatkan jumlah penonton menjadi banyak dan tidak terkontrol (Andrei, 2019). Walaupun ada perbedaan pendapat terkait penyebab kerusuhan ketika itu, skena metal memiliki peran penting dalam turunnya Orde Baru. Jeremy Wallach berpendapat metal memiliki pengaruh secara tidak langsung melalui mahasiswa di kampus-kampus yang mendengarkan musik metal dan membaca zine z $^{3}$ yang mempengaruhi pergerakan mereka (Jakartapost, 2017). Pasca Orde Baru berkuasa, menjadi babak baru skena musik metal di Indonesia karena perubahan sosial, ekonomi dan politik, hal ini membuat genre dan tema musik metal menjadi lebih variatif.

Pada 2008 misalnya band Funeral Inception menerbitkan album bertema Heathen Against Terrorizing Entities yang betujuan untuk mengkritik politik atas nama agama Islam yang terjadi pada saat itu (Putra, 2018). Kebangkitan Islam ekstrimis yang melakukan teror di mana-mana, menjadi latar belakang album ini diciptakan, meskipun mengkritisi politik Islam ekstrim ketika itu, mayoritas muslim di Indonesia tidak merasa terganggu.

Pada saat bersamaan pasca Orde Baru umat muslim juga mendapat kebebasan untuk mengekspresikan keislaman, lebih dari sebelumnya. Hal ini mengarah pada proses Islamisasi, yang diartikulasi melalui partai-partai politik Islam baru, kebangkitan kelompok Islam radikal dan kebebasan mengekspresi identitas agama di depan umum yang tidak dapat diungkapkan. Terlepas dari pasca Orde Baru, identitas keislaman telah mulai diartikulasikan dalam politik semenjak masa kolonialisme. Meskipun begitu setelah Indonesia merdeka 1945 pemimpin-pemimpin Islam dan partai Islam tetap berusaha untuk mengadopsi hukum-hukum Syariah ke dalam konstitusi negara, tetapi mengalami kegagalan (Baswedan, 2004). Islam di Indonesia sendiri tidak hanya menjadi wacana politik semata akan tetapi menjadi gaya hidup seperti spiritual, budaya dan ekonomi.

\footnotetext{
${ }^{3}$ Zine adalah media informasi cetak yang dikelola secara mandiri oleh komunitas undergraound dan didistribusikan secara terbatas dan gratis diantara komunitas mereka untuk alasan idealisme meskipun dikelola secara non professional (Budiman 2014).
} 
Hal itu terlihat ketika banyaknya ruang publik baru yang diartikulasi Islam, seperti pada film, majalah, buku-buku Islami, dan pada saat bersamaan budaya pop Muslim ikut berkembang pesat terutama melalui musik populer. Sehingga kebebasan informasi dan akses ke media untuk mempromosikan ideologi menjadi beragam (Ardhianto, 2018). Perubahan signifikan ini menandai era Islam populer yang bersamaan dengan tren percepatan komersialisasi budaya populer dan Islam konservatif di Indonesia, yang memengaruhi cara mengungkapkan kesalehan konservatif model baru, yang telah mengambil bentuk budaya Barat, sehingga mengalami banyak persinggungan antara Islam dan Barat, yang sebelumnya tidak pernah dibayangkan (Fealy \& White, 2008; Bruinessen, 2013; Ardhianto, 2018)

Pada masa ini, metal Islam mulai lahir, yang sebelumnya diikuti dengan gelombang musisi underground hijrah dahulu, seperti one finger movement di Jakarta, shift ${ }^{4}$ di Bandung dan masih banayak lagi komunitas kajian-kajian Islam lainya. Komunitas-komunitas tersebut menanungi musisi dan anak-anak underground, baik itu dari kalangan metal, punk dan genre musik underground lainnya (Saefullah, 2017). Fenomena hijrah sendiri lebih banyak terjadi di perkotaan, karena menurut Greg Fealy and Sally White (2008) ekspresi keimanan dalam Islam mengalami urbanisasi dan moderenisasi. Sehingga tanpa dipungkiri masyarakat perkotaan seperti Jakarta dan Bandung menjadi tempat lahirnya komunitas-komunitas hijrah. Hal ini didorong dengan hadirnya platform teknologi seperti Facebook, Instagram, Whatsapp dan lain-lain yang memberikan kemudahan bagi komunitas-komunitas tersebut untuk berinteraksi di antara mereka.

Menurut Saefullah, dalam fenomena musisi underground hijrah yang terjadi di Indonesia tidak bisa dilihat sebagai fenomena yang sama seperti kebangkitan fundamentalisme Islam ${ }^{5}$. Seperti lahirnya gerakan ekstrim dan radikal, yang selama ini sering digambarakan sebagai kebangkitan Islam di Indonesia dan beberapa negara muslim lainya. Meskipun begitu Saefullah mengatakan beberapa musisi hijrah atau komunitas musisi hijrah memiliki kecondongan seperti itu, akan tetapi dalam skena

\footnotetext{
${ }^{4}$ Komunitas hijrah yang didirikan Ustazd Hanan Attaki (UHA) yang memiliki kegiatan dakwah diakalngan anak muda dan tidak hanya terbatas di Bandung, karena melakukan tour dakwah ke daerahdaerah seperti Palu, Samrinda dan Surabaya.

${ }^{5}$ Kelompok fundamentalisme Islam yang dimaksud ialah kelompok Islam revivalis yang inging mengembalikan kejayaan Islam dengan, mengartikan kitab suci secara tekstual dan mengeksklusifkan kelompok mereka.
} 
underground di Indonesia sendiri memiliki pandangan sosial politik dan Islam yang berbeda-beda. Fenomena hijrah yang terjadi di Indonesia tidak hanya membawa satu narasi Islam, mengingat fenomena musisi hijrah tidak hanya dipengaruhi oleh nilai-nilai Islam yang ada di Indonesia akan tetapi juga dipengaruhi oleh gerakan Islam dari luar Indonesia seperti gerakan dakwah Jamaah Tablig dan Wahabi Salafi. Dengan demikian fenomena musisi hijrah tidak bisa digeneralisasi keseluruhannya sebagai satu fenomena yang sama. Jika dikelompokkan, fenomena musisi hijrah bisa dibagi menjadi dua kelompok, yaitu moderat dan pemurnian agama. Kelompok pemurni agama dalam musisi hijrah sendiri memiliki pengaruh kuat dari kelompok dakwah Islam Salafi atau sering dikenal dengan Wahabbi Salafi, itu sesuai dalam penelitian Saefullah sendiri yang mengatakan beberapa musisi-musisi hijrah underground memiliki paham atau doktrin Salafi Wahabi.

Kelompok pemurnian agama dalam musisi hijrah ini, merupakan kelompok musisi Islam yang memiliki pandangan sendiri terkait haramnya musik. Pandangan mereka juga didasarkan pada hadits Nabi Muhammad SAW. Salafi sendiri diasosiasikan dengan banyak gerakan dari gerakan radikal sampai gerakan pemurnian agama tanpa kekerasan, gerakan ini dimaksudkan untuk menghindari inovasi agama, dengan cara ketat meniru model Nabi Muhammad SAW (Wiktorowicz. 2006). Al dari band Purgatory menyatakan mantan vokalisnya Madmor juga meninggalkan musik dikarenakan, menurut pendapat Madmor sendiri, yaitu musik haram. Pernyataan tersebut di keluarkan, karena berdasar penuturan Al, Madmor memiliki haluan paham Salafi (Al, 2019). Sehingga pendapat musik haram sendiri pernah menjadi konflik dikalangan musisi undergraound pada 2015 dan mengalami banyak pedebatan (Saefullah, 2017).

Kemudian kelompok musisi hijrah moderat, memiliki pandangan musik tidak haram dengan syarat-syarat tertentu yang sesuai dengan nilai Islam dan tidak melanggar nilai-nilai tersebut. Pandangan ini menjadi dasar lahirnya musik bertemakan Islam di Indonesia seperti metal Islam. Pandangan ini didasarkan pada pandangan ulama-ulama dari lembaga dakwah terbesar di Indonesia seperti Nahdlatul'Ulama dan Muhammadiyah yang menyatakan hukum musik tidak haram asalkan tidak melanggar nilai-nilai Islam (Mohammad, 2009; Muhammadiyah, 2019). Sama seperti dua organisasi keagamaan tersebut, gerakan dakwah dari luar seperti Jam'ah Tablig juga memiliki pandangan yang sama. 
Band-band metal Islam awal seperti Tengkorak, Purgatory, Kodusa yang pernah tergabung dalam acara gigs "Titik Nol: Approach Deen Avoid Sin", yang merupakan panggung pertama metal Islam yang tergabung dalam salam satu jari di Jakarta. Awalnya band-band tersebut seperti Purgatory dan Kodusa sebenarnya, telah mengusung tema Islam dalam liriknya sebelum salam satu jari dikenal (James and Walsh 2019 :288). AL dari band Purgatory juga menyatakan band Purgatory telah mengusung tema Islam sejak album pertama Abyss Call pada 1994 tetapi masih secara tersirat. Seiring pendewasaan lirik dan judul albumnya mulai disampaikan secara tersurat menyampaikan pesan Islam. ${ }^{6}$ Hal ini yang membedakannya dengan band Kodusa dan Tengkorak yang awalnya membawakan tema di luar Islam, sampai beberapa album terakhir mereka yang mulai membawakan tema Islam dan anti-zionis.

Terlepas dari perubahan sosial politik pasca Orde baru, hibridisasi Islam dan budaya populer sebenarnya sudah terjadi sebelum itu. Misalnya pada musik dangdut yang diperkenalkan Rhoma Irama yang sudah menggambarkan hibridisasi Islam dengan musik pop. Musiknya dengan genre percampuran dari banyak musik, salah satunya rock Barat (Weintraub.2011). Keterbukaan dunia Islam di Indonesia dengan budaya populer sudah menjadi hal yang lumrah, yang tergambar dengan keadaan Islam yang lebih modern dan moderat. Keadaan ini sebenarnya menunjukan bagaimana modernisasi yang selama ini dibayangkan sebagai sekulerisasi tidak selamanya menjadi sekuler, bahkan religuistitas bisa bertahan dalam modernisasi (Ariel Heryanto, 2016). Pembeda antara masa Orde Baru dan setelahnya adalah globalisasi budaya yang terjadi lebih cepat, sehingga artikulasi Islam dengan budaya lain semakin luas.

Jika menelaah lebih jauh percampuran Islam dan metal bisa memengaruhi ajaran Sufisme yang sudah ada di Masyarakat Indonesia. Sufisme sendiri merupakan filosofi Islam yang mengajarkan untuk menjadi rendah hati dan mencari makna kehidupan dan tujuannya. Anatara Sufisme dan musik telah menjadi jembatan penghubung musik dengan Islam sejak lama, seperti musik folk Sunda yang menggambarkan percampuran musik budaya tradisional dan Sufisme Islam. Kemudian gamelan musik tradisional Jawa juga memiliki ikatan kuat dengan nilai Sufism Islam (Walton, 2007). Ajaran Sufisme dalam Islam juga memungkinkan percampuran atau sinkretisme antara Islam dan musik

\footnotetext{
${ }^{6}$ Wawancara pada 14 Agustus 2019 dengan AL Drummer Purgatory dikediamannya sekaligus basecame Purgatory di Komp. Kembang Larangan, Jl. Lempuyang 1 No.15, Ciledug Tangerang.
} 
populer dalam kontek metal Islam. Karena sufisme sering dikaitkan dengan kosmopolitanisme Islam yang terjadi dalam globalisasi (Cesari, 2011), meskipun sufisme dalam musik tradisonal Indonesia memiliki makna tersirat.

Metal Islam yang pertama di perkenalkan oleh band-band tersebut sempat dikira akan redup dan tidak eksis lagi, karena Ombat, bandnya dan komunitas salam satu jari tidak eksis lagi. Meskipun begitu eksistensi band-band metal Islam di Indonesia masih ada, bahkan band Purgatory masih ada dan berdasarkan pernyataan dari Al dalam waktu yang dekat akan merencanakan pembuatan album baru (Al, 2019), begitu juga band-band metal Islam lainya masih tetap eksis seperti Saffar dan Restlesst di Bandung.

\section{Transformasi Metal ke Metal Islam di Indonesia}

Hibridisasi musik tidak hanya berbicara musik dari artistik atau percampuran antara genre musik satu dengan yang lain, tetapi melampaui itu. Sebab musik selama ini tidak hanya dipahami sebagai seni saja karena musik memiliki nilai ideologi, identitas, gaya hidup dan semangat perlawanan yang disuarakan. Sebab itu melalui hibridisasi yang terjadi dalam musik metal dan Islam juga akan mengubah nilai yang sudah ada di antara keduanya.

Hal serupa pun terjadi di metal, yang diasosiasikan dengan ideologi satanic yang mengarah pada anti-Kristen, terutama genre black metal dan death metal yang sering dianggap sebagai genre yang mempromosikan ideologi tesebut (Cordero, 2009). Meskipun begitu tidak ada titik jelas hubungan antara metal dengan ideologi Satanic, karena metal sebagai seni bermusik memiliki tendensi untuk digunakan oleh kelompok ideologi tertentu untuk tujuan ideologis. Seperti white metal misalnya menyuarakan semangat Kristen di Barat melalui musik metal. Hal serupa juga terjadi dalam metal Islam di Indonesia, dari segi seni bermusik band-band metal Islam di Indonesia tidak berbeda dengan band-band metal kebanyakan. Pembedanya hanya pada ide, judul album, pidato konser dan lirik mereka yang mengarah pada pesan-pesan Islam yang berasal dari beberapa sumber, seperti Al-quran, Hadist, sejarah, politik Islam dan keadaan sosial masyarakat Islam di Indonesia. Misalnya, Purgatory melalui judul album “7:172" merujuk pada surat dalam Al-quran yaitu Surat ke 7 Al-a'raaf, sedangkan 172 merujuk pada ayat 172 pada surat tersebut. Berdasarkan judul album tersebut Al dan personil Purgatory yang lain ingin menjelaskan bagaimana manusia sejak awal, sebelum mereka lahir di Bumi ketika masih dalam Rahim telah bersaksi bahwa Allah SWT adalah 
tuhannya 172 (Al, 2019). Berbeda dengan band Purgatory, Shamir menuturkan bahwa band Tengkorak lebih banyak menyampaikan pesan-pesan Islam dalam konsernya, seperti melakukan pidato atau ceramah singkat ajakan tentang Islam di atas panggung. Menurut Shamir konser merupakan tempat terbaik mendengarkan musik metal, karena menurutnya metal merupakan musik panggung yang lebih bisa dinikmati secara live, hal tersebut membuat band Tengkorak merasa panggung tempat terbaik untuk menyampikan pesan-pesan dakwah. Sehingga tanpa dipungkiri konser musik juga merupakan cara mengekpresikan musik tersebut (Wallach \& Levine., 2012). Jika melihat perkembangan skena metal di Indonesia, tema agama tidak pernah sebelumnya dibawakan. Karena ini bertolak belakang dengan keadaan metalhead di Indonesia selama ini, yang telah menjadikan agama sebagai ranah privat dan itu menjadi hubungan secara pribadi para metalhead di antara mereka (Wallach, 2011).

Metal Islam juga mengubah kebiasaan atau attitude dalam metal yang selama ini melekat kuat. Seperti mentranformasi salam metal tiga jari atau salam devil houns menjadi salam satu jari yang diasosiasikan dengan tauwhid atau monotisme yang ada dalam kepercayaan Islam. Kemudian mengubah image alkohol, free sex dan tato. Shamir mengatakan untuk menjadi metalhead tidak harus minum atau bertato. Sebagai musisi metal dan panutan para metalhead yang mendengarkan musiknya, Shamir merasa memiliki beban moral untuk menyampaikan dan mengubah kebiasan tersebut, karena gaya hidup musisi juga menjadi pesan dalam musiknya (Hidayatullah).

Dalam sebuah wawancara dengan media asing, vokalis Tengkorak menyatakan tentang imperialisme budaya. Ombat mempercayai bahwa budaya underground metal yang dia konsumsi adalah bagian dari fikri Ghazwul atau invasi pikiran oleh Barat untuk merusak pemuda muslim Indonesia, yang memengaruhi anak-anak muda mengkonsumsi obat-obatan terlarang, alkohol dan pornografi, yang biasa ditemukan dalam komunitas underground metal (Saefullah 2017). Ini yang melatarbelakangi band Tengkorak memperjuangkan nilai Islam dalam skena metal di Indonesia.

Mekipun begitu pandangan terkait imperialisme baru melalui budaya metal atau underground secara umum, tidak sepenuhnya yang menjadi cikal band-band terbentuknya metal Islam di Indonesia, seperti yang dinyatakan Ombat. Band Purgatory misalnya, berdasarkan penuturan Al, menyatakan bandnya tidak melihat metal sebagai bentuk imperialisme baru yang harus ditaklukkan, tetapi menurut $\mathrm{Al}$, bandnya membawakan pesan Islam karena Islam merupakan hal yang dekat dan yang dia mengerti. 
Al menyatakan dari kecil dia diajar mengaji, ibadah dan dididik dengan nilai Islam oleh keluarga. Sehingga wajar menurutnya untuk membawakan tema Islam (Al, 2019). Hal serupa juga dituturkan oleh band-band metal Islam seperti Restless dan Latahzan yang memiliki motifasi yang sama karena pengalaman hidup mereka yang dekat dengan ajaran Islam.

Skena underground dan termasuk metal di Indonesia selama ini telah menjadi tempat lahirnya perkumpulan lintas kelas, semua orang bisa berpartisifasi dan ikut didalamnya tanpa dibedakan ekonomi, pendidikan dan agama (Bodden, 2005). Sehingga ketika metal Islam lahir, pola identitas dalam metal juga ikut berubah, yang selama ini tidak digunakan untuk mengakomodasi identitas tertentu, sekarang digunakan untuk mengakomodasi identitas Islam. Perubahan ini dalam hibridisasi budaya menggambarkan orang menegaskan loyalitas lokal tetapi ingin tetap berbagi dalam nilai-nilai dan gaya hidup global (Lipschutz, 1992). Perubahan identitas ini telah memodifikasi pola praktik dalam metal Indonesia, seperti perubahan pola komunitas metal yang mengarah pada eksklusifitas dalam inklusifitas, seperti salam satu jari.

Menurut Ferdhi F. Putra (2018) skena musik underground yang ada di Indonesia terutama skena metal berbeda dengan yang berada di Barat. Terlihat band-band metal Indonesia tidak seutuhnya meniru Barat, tetapi skena metal yang lahir di Indonesia juga dibentuk oleh realitas dalam masyarakat seperti identitas lokal dan budaya lokal. Hal itu juga melatarbelakangi band-band metal Islam yang lahir di Indonesia. Metal Islam sendiri memberikan identitas hibrida baru dalam skena metal di Indonesia dan menjadi identitas alternatif.

\section{Dinamika Metal Islam di Indonesia}

Musik dalam Islam adalah sesuatu yang dilarang atau haram itu merupakan hal yang sering didengar dari segelintiran muslim dan para orientalis. Meskipun begitu dalam Islam sendiri, hukum tentang musik masih diperdebatkan di antara kalangan ulama-ulama atau ilmuwan-ilmuwan Islam saat ini. Musik dan Islam di Indonesia sendiri telah berakulturasi dengan budaya setempat seperti melalui musik gamelan yang menurut beberapa orang mengajarkan sufisme (Walton 2007). Meskipun begitu, hukum musik dan Islam masih menjadi perdebatan di Indonesia, antara kelompok-kelompok Islam. Terlepas dari organisasi masyarkat terbesar seperti Muhammadiyah dan NU telah berpandangan hukum musik itu boleh, dengan ketentuan-ketentuan Islam (Suara 
Muhammadiyah, 2019). Perdebatan terkait hukum musik ini kembali diperdebatkan karena pengaruh gerakan transnasional dakwah Islam, yang baru diterima secara luas sebagai pemahaman dan praktik keislaman di Indonesia yang mulai beragam, seperti Jam'ah Tablig dan Salafi. Oleh sebab itu pengaruh gerakan tersebut memperpanjang pedebatan sebelumnya.

Keragaman pemahaman Islam yang berkembang memberikan interpretasi berbeda terkait pemahaman musik dan Islam dalam konteks ini. Misalnya seperti Salafi yang dijelaskan pada sub tema di atas, yang lebih ketat dalam melihat hukum musik yang didasarkan pada dalil tekstual dari hadist nabi. Kemudian kelompok paham ini juga tumbuh dikalangan musisi underground hijrah, sesuai dengan pernyataan (Saefullah, 2017) yang mengatakan beberapa musisi hijrah underground memiliki paham atau doktrin Salafi Wahabi. Paham kelompok ini bertujuan untuk menghentikan orang dari bentuk perilaku inovasi agama atau tidak Islami, seperti bermain dan mendengarkan musik (Gauvain, 2010:807). Paham ini sering mengalami gesekan di Indonesia, karena nilai sufisme yang masih hidup di masyarakat muslim Indonesia. Gesekan diantara kedua paham ini terjadi karena menurut pemahaman Salafi, apa yang diajarkan dalam pemahaman sufisme tentang Islam tidak sesuai dengan apa yang diajarkan Nabi (Howell, 2010 ). Hal serupa pun terjadi ketika metal Islam mulai hadir dalam skena underground. Bagi kelompok paham Salafi sendiri tidak ada musik dalam Islam, apalagi menggabungkan Islam dengan musik metal. Oleh karena itu pada 2015 dikalangan musisi underground hijrah dan mengalami banyak perdebatan tentang musik itu haram atau tidak (Saefullah, 2017).

Kontra terhadap lahirnya metal Islam juga terjadi di kalangan skena metal. Terutama ketika salam satu jari dikenal sebagai komuitas underground hijrah pertama yang memperkenalkan salam satu jari sebagai pengganti salam tiga jari ala metal. Salam satu jari dianggap mendukung fundamentalisme Islam dan mengenyampingkan musisi dan fans non-Muslim atau non-fundamentalis dari partisipasi dalam metal di Indonesia. Hal ini ditakutkan akan memecah metal yang sebelumnya menjadi tempat bagi semua identitas menjadi faksi-faksi berdasarkan aliansi agama. Selain itu juga ditakutkan skena metal menjadi tempat ideologi ekstremis Muslim dan bahkan terorisme tumbuh subur (Moore, 2013). Ketakutan itu terjadi karena kedekatan Ombat pendiri salam satu jari dengan tokoh fundamentalisme Islam, Habib Rizeq yang juga merupakan pediri FPI. Selain itu keterlibatan Ombat sendiri, yang sekaligus sebagai ketua, dalam pusat hak asasi 
manusia muslim (PUSHAMI) yang didirikan bersama FPI. Kemudian ketakutan lainnya adalah serangan teror ISIS Januari 2016 di Jakarta yang diasosiasikan dengan salam satu jari, dengan Bahrun Naim sebagai tersangka yang tertangkap dianggap sebagai pendiri salam satu jari, tetapi Ombat membatah dugaan itu (Saefullah, 2017).

Sebagai reaksi terhadap salam satu jari pada saat itu, Wendi Putranto seorang pengiat musik metal dan Arian13 dari band Seringai membuat akun Facebook counter group yang diberi nama "Metal Untuk Semua". Wendi dan Arian13 menggambarkan grup ini adalah gerakan musik metal yang terbuka untuk semua kelas, suku, agama, ras, genre musik dan pilihan dari setiap dan menolakan terhadap semua bentuk kekerasan dan terorisme (Moore, 2013). Setelah itu berdasarkan pendapat Andre dari Siksa Kubur band, yang kontra terhadap salam satu jari yang berada di skena metal Jakarta waktu itu, membuat acara konser tandingan dengan tema "Metal untuk Semua": Konser ProPluralisme dan Anti-terorisme" yang diisi oleh band-band di luar salam satu jari (Andrei, 2019) Konser tandingan ini memberi pengertian bahwa skena underground terutama metal bukan lahir dari konservatif (Putra, 2018).

Keadaan tersebut membuat band metal Islam di Jakarta seperti Purgatory cukup sulit untuk mendapatkan panggung untuk pentas. Padahal sebelumnya, berdasarkan keterangan Al, Purgatory sebagai salah satu band metal Islam awal bisa diterima di kalangan metal. Bahkan Al menceritakan Purgatory sempat manggung di Hard Rock Jakarta dan mengucapkan takbir "Allahuakbar" dalam perfomanya (AL, 2019). Lutfi gitaris Purgatory menyatakan keberadaan Purgatory sebagai metal Islam membuat Purgatory menjadi band metal paling underground karena membawakan tema Islam yang tidak sepenuhnya bisa diterima oleh beberapa skena metal Jakarta, sehingga menurut Lutfi memainkan musik underground dengan tema anti mainstream membuat Purgatory lebih underground dari underground dan metal Islam terpinggirkan di skena metal Indonesia.

Perlawan terhadap metal Islam di Indonesia sendiri hanya terjadi di skena metal di Jakarta. Karena berdasarkan keterangan dari Shule Restless, di skena metal Bandung sendiri, Restless dan beberapa band metal Islam lainnya, seperti Hizjrah dan Saffar mislanya, di terima secara baik oleh skena metal Bandung dan tetap bisa meramaikan skena metal di Bandung sampai saat ini. Meskipun sebelumnya Shule menyatakan merasakan dampak secara tidak langsung dari konflik salam satu jari di Jakarta. Menurut 
Shule konflik salam satu jari di Jakarta sendiri lebih karena skena Jakarta memiliki persaingan yang lebih sengit, karena berasal dari berbagai identitas yang berbeda. Keadaan ini berbeda dengan skena Bandung yang lebih homogen. Pernyataan itu juga dinyatakan Andrei, bahwasanya skena Jakarta mengalami perpecahan diantara band-band karena konflik kepentingan diantara mereka. Andrei juga mengatakan konflik salam satu jari yang terjadi di Jakarta hanya terbatas antara band-band metal di Jakarta dan tidak samapi ke fans atau metalhead (Andrei, 2019).

Berbeda dengan band-band metal Islam generasi awal di Jakarta, band-band metal Islam seperti Latahzan asal Purbalingga. Tentara Tuhan, Hijrah dan Mujahid Grind dari Malang, tidak merasakan konflik yang terjadi di skena Jakarta. Fatih mengatakan band Latahzan sering manggung bersama band-band death metal lain di Purbalingga dan Purwokerto tanpa membedakan sebagai band metal Islam seperti di Jakarta dan itu juga terjadi di daerah-daerah lain seperti yang dialami oleh band Restless (Fatih, 2019). Seiring hilangnya salam satu jari, konflik di skena metal Jakarta berangsur hilang. Meskipun begitu band-band yang tergabung dalam 'satu jari', seperti Purgatory, Aftermath dan Kodusa masih eksis sampai saat ini. Setelah sekian lama konflik itu, sekarang Andre menyadari bahwa selain konten yang dibawakan lebih Islami, 'salam satu jari' tidak ada bedanya dengan band-band metal lain (Andrei, 2019). Bahkan komunitas one finger movement Malang beberapa waktu lalu bahkan membuat panggung bersama dengan band-band metal di luar mereka, dengan mengangkat tema respect another scene.

Terlepas dari dinamika yang terjadi dari awal sampai saat ini, metal Islam telah menjadi sub genre baru dalam metal Indonesia. Dari waktu ke waktu banyak band-band metal Islam yang lahir, meskipun dalam penelitian ini tidak dituliskan keseluruhan karena keterbatasan penelitian, sehingga keberadaan metal Islam di Indonesia masih tetap eksis.

\section{Simpulan}

Tulisan ini memperlihatkan bagaimana globalisasi mempetemukan antara budaya lintas nasional yang tidak dibayangkan sebelumnya. Band-band metal Islam di Indonesia jelas menggambarkan fenomena tersebut. Metal Islam menegaskan proses hibridisasi bisa juga terjadi dikalangan fundamentalisme dan Barat. Kemungkinan itu terjadi, karena kehadiran budaya lain seperti budaya metal membuka ruang publik baru bagi kalangan fundamentalisme untuk mengartikulasikan identitas mereka melalui metal. 
Budaya metal telah memberikan pengalaman identitas transnasional bagi kalangan muslim di Indonesia. Meskipun begitu penegasan terhadap identitas asli juga semakin menguat walaupun telah mengalami hibridisasi, band-band metal Islam ini menegaskan identitas dengan menunjukan diri mereka sebagai band metal dengan identitas Islam.

\section{References}

AL. (2019, 8 14). Wawancara dengan Drummer Purgatory. (Penulis, Interviewer) Andrei. (2019, 8 15). Wawancara dengan Gitaris Siksa Kubur. (Peneliti, Interviewer) Ardhianto, I. (2018, June). Contemporary Islamic Movement, Popular Culture and Public Sphere in Indonesia: The \#IndonesiaTanpa JIL Movement . Archipel, 95 , 151-71. doi:10.4000/archipel.652

Ariel Heryanto. (2016). Upgraded piety and pleasure: the new middle class and Islam in Indonesia popular culture. In A. N. Weintraub, Islam and Popular Culture in Indonesia and Malaysia (pp. 60-82). New York: Routledge.

Baswedan, A. R. (2004). Political Islam in Indonesia: Present and Future Trajectory. Asian Survey, 44(5), 669-90. doi:10.1525/as.2004.44.5.669

Baulch, E. (2002). Alternative Music and Mediation in Late New Order Indonesia. InterAsia Cultural Studies, 3(2), 219-34. doi:10.1080/1464937022000000138

Beck, U., Sznaider, N., \& Winter, R. (2003). Global America? The Cultural Consequences of Globalization. Studies in Social and Political Thought . Liverpool: Liverpool University. Press.

Bodden, M. (2005). Rap in Indonesian Youth Music of the 1990s: Globalization; Outlaw Genres, and Social Protest. Asian Music, 36(2), 1-26. doi:10.1353/amu.2005.0015

Bossius, Thomas; Häger, Andreas; Kahn-Harris, Keith. (2011). . Religion and Popular Music in Europe: New Expressions of Sacred and Secular Identity (Vol. 18). London : I.B. Taurus.

Bruinessen, M. v. (2013). Introduction: Contemporary Developments in Indonesia. In M. v. Bruinessen, Explaining the Conservative Turn. Singapore: Institute of Southeast Asian Studies.

Cesari, J. (2011). Global Islam: Between fundamentalism and cosmopolitanism. .Gordonsville: Palgrave MacMillan.

Cordero, J. ( 2009). Unveiling Satan's Wrath: Aesthetics and Ideology in Anti-Christian Heavy Metal . The Journal of Religion and Popular Culture , 21 (1), 5-5. doi:10.3138/jrpc.21.1.005

Fatih. (2019, 8 21). Wawancara dengan Vokalis Latahzan. (Peneliti, Interviewer)

Fealy, G., \& White, S. (2008 ). Expressing Islam: Religious Life and Politics in Indonesia. Singapore: Institute of Southeast Asian Studies.

Gauvain, R. ( 2010). Salafism in Modern Egypt: Panacea or Pest? Political Theology, 11(6), 802-25. doi:10.1558/poth.v11i6.802

Hannerz, U. (2006). Two Faces of Cosmopolitanism: Culture and Politics. Barcelona: Fundació CIDOB. 
Held, D. (2003). Cosmopolitanism: taming globalization. In D. Held, \& A. McGrew, The Global Transformations Reader: an Introduction to the Globalization Debate (pp. 514-529). Cambridge: Polity Press.

Heryanto, A. (1995). What Does Post-Modernism Do in Contemporary Indonesia? Sojourn: Journal of Social Issues in Southeast Asia, 10 ( 1), 33-44.

Hidayatullah, R. (n.d.). Academia.edu. Retrieved from Academia.edu: https://www.academia.edu/29235759/SUBKULTUR_METAL_ISLAM_DI_INDO NESIA_ARTIKULASI_IDENTITAS_DALAM_PUSARAN_BUDAYA_GLOBA $\mathrm{L}$

Hjelm, T., Kahn-Harris, K., \& LeVine., M. (2011). "Heavy Metal as Controversy and Counterculture." . Popular Music History, 6(1), 5-18. doi:doi:10.1558/pomh.v6i1/2.5

Hoesterey, J. B. (2012 ). Prophetic Cosmopolitanism: Islam, Pop Psychology, and Civic Virtue in Indonesia. City \& Society , 24 (1), 38-61. doi:10.1111/j.1548744X.2012.01067.x.

Hoestery, J. B. (2012). Prophetic Cosmopolitanism: Islam, Pop Psychology, and Civic Virtue in Indonesia. City \& Society, 24(1), 38-61. doi:10.1111/j.1548744X.2012.01067.x

Holton, R. (2000, July 1). Globalization's Cultural Consequences. The ANNALS of the American Academy of Political and Social Science, 570, 140-152. doi:doi.org/10.1177/000271620057000111

Howell, J. (2010 ). Indonesia's Salafist Sufis . Modern Asian Studies , 44 (5), 1029-51. doi:10.1017/S0026749X09990278

James, K., \& Walsh., R. (2019). James, Kieran, and Rex Walsh. 2019. "Religion and Heavy Metal Music in Indonesia." Popular Music 38 (2): 276-97. https://doi.org/10.1017/S0261143019000102. Popular Music, 38 (2), 276-97. doi:doi.org/10.1017/S0261143019000102.

Kersten, C. (2009). Islam, Cultural Hybridity and Cosmopolitanism: New Muslim Intellectuals on Globalization. Journal of International and Global Studies, 1(1), 89113.

Kersten, C. (2009). Islam, Cultural Hybridity and Cosmopolitanism: New Muslim Intellectuals on Globalization. Journal of International and Global Studies, 1(1), 89113. Retrieved 2018

Kersten, C. (2009). Islam, Cultural Hybridity and Cosmopolitanism: New Muslim Intellectuals on Globalization. Journal of International and Global Studies, 89-113.

Kong, L. (1995). Music and Cultural Politics: Ideology and Resistance in Singapore. Transactions of the Institute of British Geographers , 20(4), 447. doi: $10.2307 / 622975$.

Kong, L. (Kong, Lily. 1995. "Music and Cultural Politics: Ideology and Resistance in Singapore." Transactions of the Institute of British Geographers 20 (4): 447. https://doi.org/10.2307/622975.). Music and Cultural Politics: Ideology and Resistance in Singapore. Transactions of the Institute of British Geographers , 20 (4), 447. doi:10.2307/622975.

Kraidy, M. M. (2002). Hybridity in Cultural Globalization. Communication Theory, 12(3), 316-339. doi:10.1111/j.1468-2885.2002.tb00272.x.

Kwok-Bun, C. (2005). Chinese Identities, Ethnicity and Cosmopolitanism. London: Routledge.

Kwok-Bun, C. (2005). Chinese Identities, Ethnicity and Cosmopolitanism. London: Routledge. 
LeVine, M. (2008.). Heavy Metal Islam: Rock, Resistance, and the Struggle for the Soul of Islam. New York: Three Rivers Press.

Levine, M. (2009). Headbanging againt repressive regimes lensorship of heavy metal in Middel East, North Africa, Southeast Asia and China. Denmark: Freemuse.

Lipschutz, R. D. (1992). Reconstructing World Politics: The Emergence of Global Civil Society. Millennium: Journal of International Studies, 21(3), 389-420. doi:10.1177/03058298920210031001

Mehta, P. B. (2000). Cosmopolitanism and the Circle of Reason. Political Theory, 28(5), 619-39. doi:10.1177/0090591700028005003

Mohammad, J. (2009, $10 \quad 1)$. NU. Retrieved from NU: https://www.nu.or.id/post/read/19340/pandangan-ulama-terhadap-seni-musik.

Moore, R. E. (2013). My Music, My Freedom(?): The Troubled Pursuit of Musical and Intellectual Independence on the Internet in Indonesia . Asian Journal of Communication , 23 (4), 368-85. doi:10.1080/01292986.2013.804105

Muhammadiyah, S. (2019, 4 5). Retrieved from Suara Muhammadiyah: http://www.suaramuhammadiyah.id/2019/04/05/hukum-musik/

Patton, M. Q., \& Cochran, M. (2002). A Guide to Using Qualitative Research Methodology. London: Research Officer, MSF UK.

Philipp, S. (2012). Conceptualizing Cultural Hybridization: A Transdisciplinary Approach. Transcultural Research. Heidelberg Studies on Asia and Europe in a Global Context. New York: Springer.

Pieterse, J. N. (2009). Globalization and Culture: Global Mélange (2 ed.). Lanham, Maryland: Rowman \& Littlefield.

Putra, F. F. (2018). Salam Satu Jari: Politik 'Ruang' Skema Musik Underground. In I. R. Darajat, Lanskap: Mosaik Musik Masyarakat. Yayasan Kajian Musik Laras.

Robertson, R. (1992). Globalization: Social Theory and Global Culture. London: SAGE Publication.

Rodan, G. (1996). Political Oppositions in Industrialising Asia. London: Routledge .

Saefullah, H. (2017). Nevermind the Jahiliyyah, Here's the Hijrahs': Punk and the Religious Turn in the Contemporary Indonesian Underground Scene. Punk \& Post Punk Saefullah, 6(2), 263-89. doi:10.1386/punk.6.2.263_1.

Thomas Bossius, Häger, Andreas, \& Kahn-Harris, K. (2011). Religion and Popular Music in Europe: New Expressions of Sacred and Secular Identity (Vol. 18). London: I.B. Taurus.

Wallach, J. (2011). Metal Rules the Globe: Heavy Metal Music around the World. London: Duke University Press.

Wallach, J., \& Levine., A. (2012). I Want You to Support Local Metal: A Theory of Metal Scene Formation. Popular Music History, 6(1), 116-34. doi:10.1558/pomh.v6i1/2.116

Walton, S. P. (2007). Aesthetic and Spiritual Correlations in Javanese Gamelan Music. Journal of Aesthetics and Art Criticism, 65 (1): 31-41. https://doi.org/10.1111/j.1540-594X.2007.00235.x.(1), 31-41. doi:10.1111/j.1540594X.2007.00235.x

Weinstein, D. 2. (2000). Heavy Metal: the Music and its Culture, revised edition. New York:: Da Capo Press.

Yeĝenoĝlu, M. ( 2005). Cosmopolitanism and Nationalism in a Globalized World. Ethnic and Racial Studies, 28(1 ), 103-31. doi:10.1080/0141987042000280030 